\title{
Epidemiology of poisoning in Bamako, Mali
}

\author{
Tidiane Diallo, ${ }^{1, *}$, Abdourahamane Diara ${ }^{1}$, Cheick Abou Coulibaly ${ }^{2}$, Alpha Traoré ${ }^{1}$, Hinde Hami ${ }^{3}$, Abdelmajid \\ Soulaymani $^{3}$, and Ababacar Maïga ${ }^{1}$ \\ ${ }^{1}$ Faculty of Pharmacy, University of Sciences, Techniques and Technologies, Bamako, Mali \\ ${ }^{2}$ Faculty of Medicine and Odonto-Stomatology, University of Sciences, Techniques and Technologies, Bamako, Mali \\ ${ }^{3}$ Laboratory of Biology and Health, Faculty of Science, Ibn Tofail University, Kenitra, Morocco
}

\begin{abstract}
Introduction: In Mali, poisoning is a public health problem through its multiple circumstances. Its management is a pre-hospital concern given the lack of qualified personnel, adequate medical equipment and lack of knowledge of the substances involved in poisoning. The aim of this study was to describe the epidemiological profile of poisoning in Bamako. Methods: The study was conducted in six Reference Health Centers in the District of Bamako. This was a retrospective study of poisoning cases covering the period from January 2010 to December 2019. The data used was collected from registers and patient medical records. Results: During the study period, we collected 2,112 cases of poisoning. The sex-ratio $(M / F)$ was 1.5 in favour of males. More than two-thirds of cases (66.7\%) were due to foodborne diseases, followed by drug poisoning, with $18.7 \%$ of cases. The majority of patients were pupils and students $(69.7 \%)$ and $5.5 \%$ were housewives. The circumstances were most often accidental, with $82 \%$ of cases. In addition, the clinical signs were dominated by gastrointestinal disorders: diarrhea (40\%), vomiting (40\%) and respiratory distress $(9.4 \%)$. Conclusion: Reducing the risk of poisoning and improving their management requires education of the population and professional training of health workers.
\end{abstract}

Keywords: Poisoning; Epidemiology; Bamako

\footnotetext{
${ }^{*}$ Corresponding author: tidiallo2017@gmail.com
} 


\section{Introduction}

In 2004, According to the World Health Organization (WHO), 346,000 people, 91\% of them in low- and middle-income countries, died from accidental poisoning worldwide [1].

Mortality from acute poisoning is fairly low, less than $1 \%$ for all drug poisoning. However, it is more important if we consider certain cardiotonic drugs or if we take into account all poisoning types [2].

Thus, between 150 and 200,000 intentional poisoning cases are hospitalized in France each year, of which nearly $90 \%$ are caused by drugs [3]. In 2006, the Poison Control Centers in France identified 197,042 cases of human exposure to toxic substances.

At the Québec Poison Control Centre between 1989 and 2007, the annual number of calls for poisoning was on average 46,946 calls [4].

In Morocco, 15,290 poisoning cases were notified to the Moroccan Poison Control Center in 2015, with a case fatality rate of $0.83 \%$ [5].

In Togo in 2020, poisoning represented $0.25 \%$ of admissions in the 2 departments of the Sylvanus Olympio University Hospital Center (CHU SO) in Lomé. About $33 \%$ of the victims were under 5 years old. Circumstances were accidental in 100 of the 201 cases. Industrial and household products were the most incriminated $(34.33 \%)$, followed by drugs $(22.29 \%)$ and psychoactive substances $(17.91 \%)$. The prognosis was unfavorable in $2.49 \%$ [6].

A study carried out in three Abidjan university hospitals from 2005 to 2011 recorded 557 cases of poisoning in children, or $8.50 \%$ of admissions to emergency and pediatric intensive care units [7].

In Mali, several studies have been carried out on the epidemiology of poisoning. Thus in 2012, the profile of poisoning was in favour of females (54.9\%). Drugs were the most incriminated (38.9\%), and $37 \%$ of poisoning cases were intentional out of a total of 1743 cases recorded in Bamako between 2000 and 2010 [8]. The case fatality rate was $146 / 3158$ or $4.6 \%$ in health centers from 2000 to 2010 [9].

Since then 2010, no centralized study on poisoning has been carried out in the reference health centers in the district of Bamako. We therefore initiated the present study with the aim of describing the epidemiological profile of poisoning in Bamako.

\section{Methods}

This was a descriptive retrospective study of poisoning cases treated in six Health Reference Centers (HRC) in the district of Bamako.

All poisoning cases admitted to the pediatric, general medicine and emergency departments of HRC and recorded in the medical records and the consultation registers over a 12-month period from December 2019 to March 2020 were concerned by this study.

Not included in this study: poisoning in newborns of an intoxicated mother, incomplete medical records, records of transferred patients.

Data were collected using a form with information contained in patient charts.

This sheet took into account other variables: the sociodemographic characteristics, the circumstances of poisoning, as well as the elements of care.

Data was entered into Microsoft Excel 2010 and statistical analysis was performed using Epi Info 7. Data was processed anonymously by assigning a number to all records.

\section{Results}

Table I. Distribution of poisoning cases according to socio-demographic characteristics

\begin{tabular}{|c|c|c|c|}
\hline Characteristics & & $\begin{array}{c}\text { Number of } \\
\text { cases }\end{array}$ & Prevalence \\
\hline \multirow{5}{*}{ Gender } & $\mathrm{F}$ & 845 & 40.00 \\
\hline & M & 1267 & 60.00 \\
\hline & Total & 2112 & 100.00 \\
\hline & Municipality I & 522 & 24.72 \\
\hline & Municipality II & 232 & 10.98 \\
\hline \multirow{7}{*}{ Place of residence } & Municipality III & 355 & 16.81 \\
\hline & Municipality IV & 373 & 17.66 \\
\hline & Municipality V & 305 & 14.44 \\
\hline & Municipality VI & 325 & 15.39 \\
\hline & Total & 2112 & 100.00 \\
\hline & [1-12 months [ & 280 & 13.26 \\
\hline & {$[1-5$ years [} & 600 & 28.41 \\
\hline \multirow[t]{4}{*}{ Age group } & {$[5-14$ years [} & 767 & 36.32 \\
\hline & {$[14-20$ years [} & 227 & 10.75 \\
\hline & {$[20-75$ years [} & 238 & 11.27 \\
\hline & Total & 2112 & 100.00 \\
\hline
\end{tabular}

In this study, $60 \%$ of cases were male, commune 1 was group [5-14[ years was the most frequent with $36.32 \%$ the most represented with $24.72 \%$ of cases and the age of cases. 


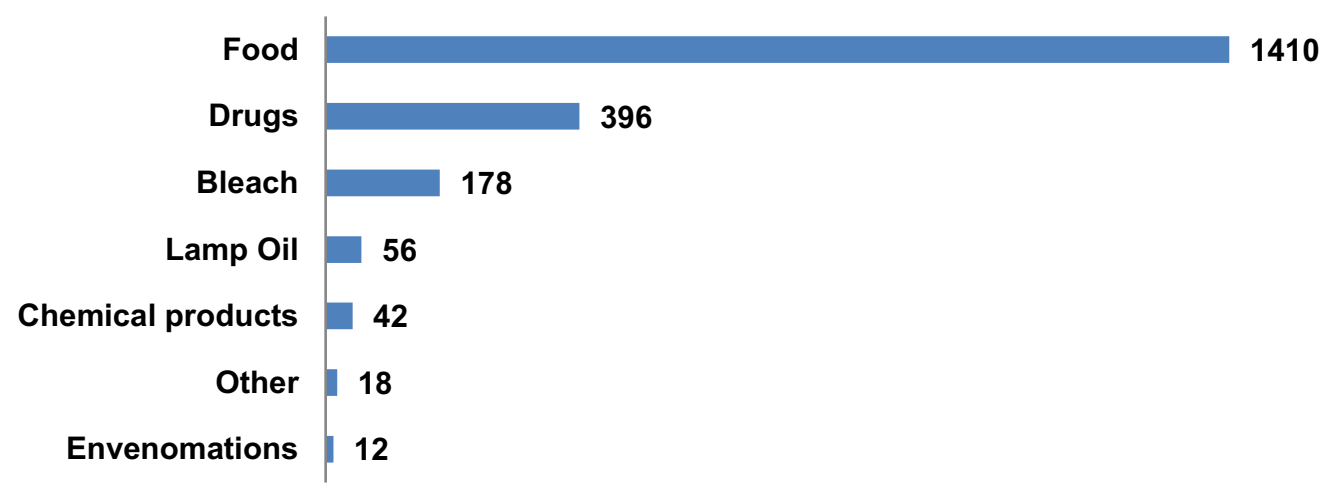

Fig. 1. Distribution of patients according to the causes of poisoning

According to the results, food was the most incriminated $(66.76 \%$ of cases), followed by drugs with $18.75 \%$ of cases.
Gastrointestinal disorders were more dominant, diarrhea and vomiting were the most marked symptoms. The treatment was symptomatic with a low rate of antidotic prescription. Circumstances of poisoning were intentional in $7 \%$ of cases.

Table II. Monthly distribution of cases by cause of poisoning

\begin{tabular}{|c|c|c|c|c|c|c|c|}
\hline \multirow[b]{2}{*}{ Months } & \multicolumn{6}{|c|}{ Poisoning causes } & \multirow[b]{2}{*}{ Total } \\
\hline & Food & Bleach & Drug & Lamp oil & Chemical products & Envenomations & \\
\hline January & 198 & 24 & 54 & 9 & 10 & 7 & 302 \\
\hline February & 133 & 16 & 51 & 8 & 4 & - & 212 \\
\hline March & 115 & 19 & 36 & 8 & 4 & - & 182 \\
\hline April & 122 & 14 & 26 & 2 & 2 & - & 166 \\
\hline May & 126 & 11 & 28 & 3 & 1 & 1 & 170 \\
\hline June & 97 & 7 & 27 & 3 & 6 & 1 & 141 \\
\hline July & 96 & 15 & 32 & 3 & 3 & 1 & 150 \\
\hline August & 104 & 15 & 25 & 2 & 1 & - & 147 \\
\hline September & 81 & 13 & 24 & 4 & 2 & 2 & 126 \\
\hline October & 91 & 16 & 30 & 1 & 5 & - & 143 \\
\hline November & 91 & 14 & 26 & 3 & 13 & - & 147 \\
\hline December & 156 & 14 & 37 & 10 & 9 & - & 226 \\
\hline Total & 1410 & 178 & 396 & 56 & 60 & 12 & 2112 \\
\hline
\end{tabular}

During the period of study, we found that January was the month when there were more cases of food poisoning with 198 cases followed by 54 cases of drug poisoning. 


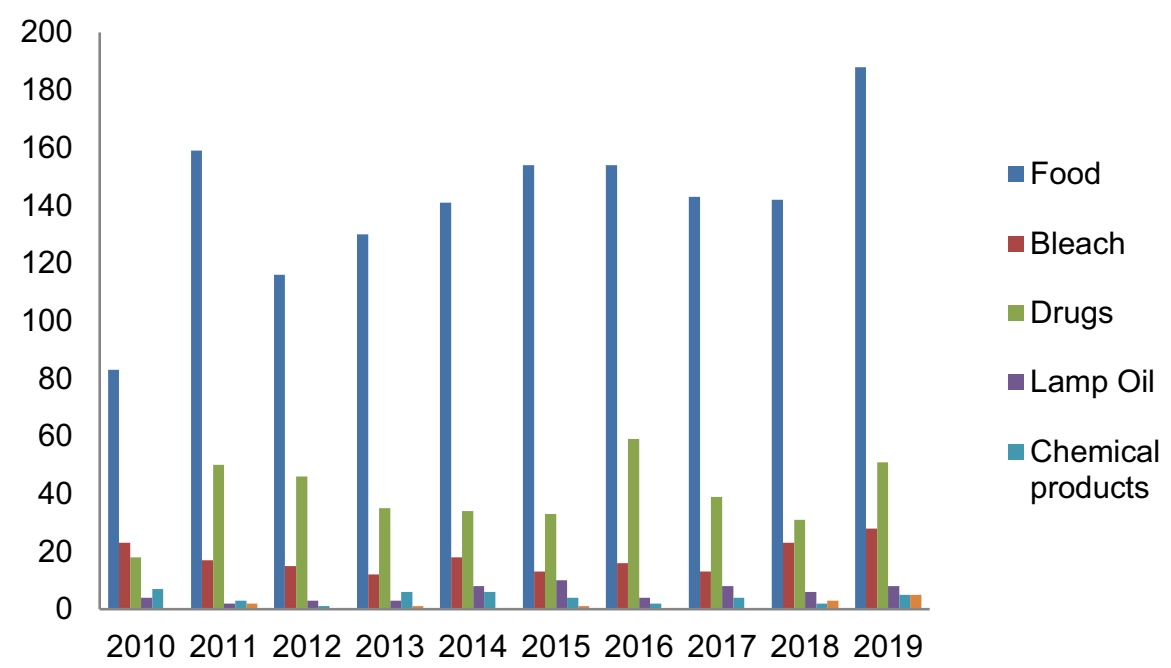

Fig. 2. Annual distribution of cases by cause of poisoning

In our study, 2019 was represented by more cases of food poisoning, i.e. 188 cases and bleach poisoning with 28 cases.
The males are the most exposed to foodborne diseases (839 cases), drug poisoning (245 cases) and bleach poisoning (102 cases).

Table III. Distribution of poisoning cases by age and cause of poisoning

\begin{tabular}{|ll|r|r|r|r|r|r|r|}
\hline & \multicolumn{7}{|c|}{ Causes of poisoning } & \\
\cline { 3 - 8 } & & Food & Bleach & Drug & Lamp oil & Chemical products & Envenomations & Total \\
\hline Age & {$[1-12$ months [ } & 149 & 80 & 28 & 12 & 11 & - & 280 \\
& [1-5 years [ & 375 & 92 & 55 & 41 & 36 & 1 & 600 \\
& [5-14 years [ & 612 & 3 & 138 & 2 & 9 & 2 & 767 \\
& [14-20 years [ & 123 & 3 & 97 & - & 2 & 227 \\
& [20-75 years [ & 151 & - & 78 & 1 & 60 & 6 & 238 \\
\hline Total & 1410 & 178 & 396 & 56 & 12 & 2112 \\
\hline
\end{tabular}

In our study, the age group [5-14[ years suffered the most food poisoning with 612 cases of food poisoning followed by 138 cases of drug poisoning.
In our study, students were the most represented with 467 cases of food poisoning followed by 179 cases of drug poisoning.

$\square$ Accidental $\square$ Voluntary

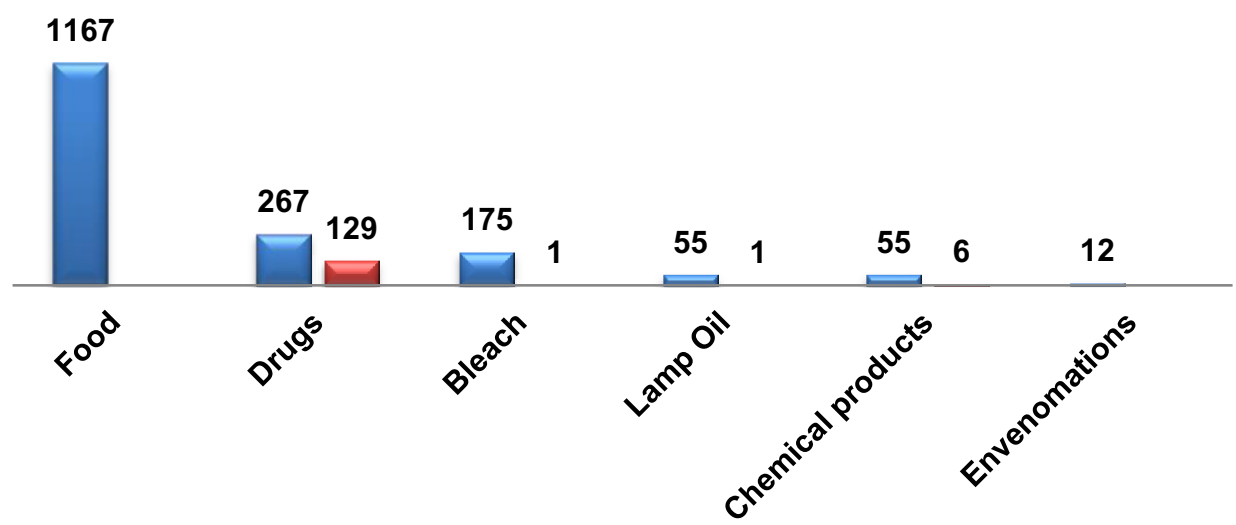

Fig. 3. Distribution of poisoning cases according to the circumstances and cause of poisoning In our study, accidental poisoning cases were the most represented, i.e. 1,167 cases. 


\section{Discussion}

In our study, 1,267 patients were male ( $60 \%$ of cases). Our results are close to those found in CHU SO of Togo, with a prevalence of $57.20 \%$ of male [6]. Diarra, in 2005 obtained $72 \%$ of cases in favour of males, which confirms the results previously obtained [10]. Our results are also different from the results of several studies: $54.93 \%$ of poisoning cases were female in Bamako between 2000 and 2010 [8] and 53\% between 2014 and 2015 [11].

The bleach, kerosene and chemical poisoning were clean for at least five years. This is explained by the lack of storage of these products as well as the hand-tomouth reflex of this age group. This result is consistent with those of Achour et al. (2012) and Diallo et al. (2016) [12, 13].

Food and drug poisoning affected the age group [5-14[ years. It was the most represented, ie $36.32 \%$. This great representativeness of this age group could be explained by the psychomotor development of the child at this age, the children are more animated by a curiosity of exploration of their entourage, which could expose them to the risk of poisoning.

According to our results, food was the most incriminated $(66.76 \%$ of cases) followed by drugs with $18.75 \%$ of cases. The predominance of foodborne diseases in our study was confirmed by a study carried out in Burkina Faso in 2006 which revealed that food products came first among the products involved in poisoning, ie $44.7 \%$ of cases [14] . In our study, the majority of poisoning cases occurred accidentally, ie $93 \%$ of cases. This result is similar to many studies [613] which would explain that poisoning is mostly accidental.

Our results showed that diarrhea and vomiting (gastrointestinal disorders) dominated the clinical signs. This result is similar to that of Diallo et al. (2012), where the clinical signs were dominated by gastrointestinal, cardiovascular, respiratory, neurological and psychological disorders [8].

Our results showed that the most common treatment for poisoning cases were symptomatic, as opposed to antidotic treatment, which was rarely used.

\section{Conclusion}

At the end of this study on the epidemiology of poisoning in the district of Bamako, we recorded several cases of poisoning, both accidental and intentional. Compared to previous results of similar studies carried out in Bamako, we have noticed an increase of more than a third of poisoning cases. The causes were numerous and varied (food, drugs ...). Regarding clinical signs: diarrhea, vomiting, agitation, respiratory distress, were the most frequent in patients. The significant increase of poisoning cases could be explained by a lack of knowledge of the conditions of conservation, use and storage of food, drugs and chemicals.
The establishment of an information and education system for the population is essential to reduce the risk of poisoning.

\section{References}

1. WHO, Prevention and management of poisoning, in https://www.who.int / poisons / Fr / Roof (2015)

2. J. Couture, M. Goulou, Recognize - Understand Treat: Emergencies, Ediseninc chap 35, 523-567 (1997)

3. P. Hantson, F. Baud, Intoxications aigues médicamenteuses, Encycl. Med. Chir. (Elsevier, Paris), Toxicologie Pathologie Professionnelle, 28p. (1995)

4. N. Mahdeb, M. Sahnoune, A. Bouzidi, European Scientific Journal, 9, 157-158 (2013)

5. R. Hmimou, N. Rhalem, H. Chaoui, I. Semlali, R. Aghandous, S. Benlarabi, M. Badri, R. Soulaymani-Bencheikh, Toxicol. Maroc, 27, 3-6 (2015)

6. T. Diallo, A. Diallo, A. Ouro-Gnagba, K.A. Djagadou, A. Diara. Analytical \& Clinical Toxicology, 32, 258-265 (2020)

7. A. Diakite, L.A. Bedib, D.S. Danoa, M. Falib, Analytical and Clinical Toxicology, 30, 106-113 (2018)

8. T. Diallo, H. Hami, A. Maïga, A. Mokhtari, A. Soulaymani, Antropo, 26, 11-18 (2012)

9. T. Diallo, D. Maïga, A. Maïga, H. Sangho, B. Coulibaly, H. Hami, A. Mokthari, R. Soulaymani, A. Soulaymani, Med. Sante Trop., 24, 183-188 (2014)

10. A. Diarra, Epidemiological, clinical and therapeutic aspects of snakebites in hospitals in Mali (Thesis in Medicine, 2005)

11. K.S. Alexandrine, Epidemiological profile of poisoning in Bamako, Mali (2014-2015) (Thesis in Pharmacy, 2015)

12. S. Achour, A. Ben Said, S. Abourazzak, N. Rhalem, A. Soulaymani, L. Ouammi, I. Semlali, R. Soulaymani Bencheikh, Toxicol. Maroc, 12, 5-8 (2012)

13. T. Diallo, A. Dénou, B.F. Coulibaly, B. Dakouo, B.Y. Koumaré, A. Maïga, Antropo, 35, 103-110 (2016)

14. F. Koueta, D. Ye, L. Dao, D. Néboua, A. Sawadogo, Health Notebooks, 17 (4), 187-191 (2007) 